\title{
PROGRAMA CURRICULAR PARA O ENSINO DE MATEMÁTICA NA DÉCADA DE 1960 - SALVADOR/BAHIA
}

\section{CURRICULUM PROGRAM FOR MATHEMATICS TEACHING IN THE 1960'S - SALVADOR/BAHIA}

\section{PROGRAMA CURRICULAR PARA LA ENSEÑANZA DE MATEMÁTICAS EN LOS 60 - SALVADOR/BAHIA}

\author{
Inês Angélica Andrade Freire* (D) 0 \\ Janice Cassia Lando** (D) $^{*}$ \\ Eliene Barbosa Lima ${ }^{* * *}$ (D) 0
}

\begin{abstract}
RESUMO
Na década de 1960, na Bahia, um grupo de professores de matemática tanto do ensino superior como da educação básica elaborou um programa curricular para o ensino de matemática no secundário, o qual foi viabilizado, em caráter experimental, por meio de apostilas e livros didáticos em sala de aula e, posteriormente, publicados e utilizados em maior escala. Assim, este artigo analisou historicamente a proposta do programa curricular de autoria do grupo de professores da Bahia, materializada na produção Coleção Matemática Moderna com saberes matemáticos e metodológicos norteados pelas recomendações internacionais do Movimento da Matemática Moderna, de forma local, historicamente situados e com uma dinâmica social que acomodou as diferentes concepções sobre os processos de ensino e de aprendizagem em matemática. A legitimidade, nesse período, de constituição de classes experimentais, possibilitou experimentações e avaliações desse programa curricular de matemática em escolas da educação básica, na cidade de Salvador, Bahia.
\end{abstract}

Palavras-chave: Movimento da Matemática Moderna. Programa Curricular de Matemática. Experimentações Pedagógicas.

\section{ABSTRACT}

In the 1960s, in Bahia, a group of mathematics teachers from higher and basic education developed a curriculum for mathematics teaching in secondary school, which was made possible, on an experimental basis, through handouts and textbooks in the classroom and later published and used on a larger scale. Thus, this article historically analyzed the proposal of the curricular program authored by the group of teachers from Bahia, materialized in the production of the Coleção Matemática Moderna

\footnotetext{
* Doutora em Ensino, Filosofia e História das Ciências pela Universidade Federal da Bahia (UFBA). Professora Adjunta da Universidade Estadual do Sudoeste da Bahia (UESB), Jequié, Bahia, Brasil. Endereço para correspondência: Caminho 01, n.13A, URBIS III, Jequiézinho, Jequié, Bahia, Brasil, CEP: 45208-589. Email: ines.angelica@uesb.edu.br.

** Doutora em Ensino, Filosofia e História das Ciências, Universidade Federal da Bahia (UFBA)/Universidade Estadual de Feira de Santana (UEFS). Professora Titular da Universidade Estadual do Sudoeste da Bahia (UESB), Jequié, Bahia, Brasil. Endereço para correspondência: Rua da Itália, n. 11, Centro, Caixa Postal 113, Jequié, Bahia, Brasil, CEP: 45.200-970. E-mail: janicelando@gmail.com.

**** Doutora em Ensino, Filosofia e História das Ciências, Universidade Federal da Bahia (UFBA)/Universidade Estadual de Feira de Santana (UEFS). Professora Titular da Universidade Estadual de Feira de Santana (UEFS), Feira de Santana, Bahia, Brasil. Endereço para correspondência: Avenida Transnordestina, s/n - Novo Horizonte, Feira de Santana, Bahia, Brasil, CEP: 44.036-900. E-mail: elienebarbosalima@ gmail.com.
} 
[Modern Mathematics Collection] with mathematical and methodological knowledge guided by the international recommendations of the Modern Mathematics Movement, locally, historically situated and with a social dynamics that accommodated the different conceptions of mathematics teaching and learning processes. The legitimacy, in this period, of the constitution of experimental classes, made possible experiments and assessments of this mathematics curriculum in basic education schools in the city of Salvador, Bahia, Brazil.

Keywords: Modern Mathematics Movement. Mathematics Curriculum Program. Pedagogical Experiments.

\section{RESUMEN}

En la década de 1960, en Bahía, un grupo de profesores de matemáticas de educación superior y básica desarrolló un plan de estudios para la enseñanza de las matemáticas en la escuela secundaria, que fue posible, de manera experimental, a través de folletos y libros de texto en el aula y luego publicado y utilizado en una escala mayor. Así, este artículo analizó históricamente la propuesta del programa curricular elaborado por el grupo de profesores de Bahía, materializado en la producción de la Coleção Matemática Moderna [Colección Matemática Moderna] con conocimientos matemáticos y metodológicos guiados por las recomendaciones internacionales del Movimiento Matemática Moderna, local e históricamente situado y con una dinámica social que acomodó las diferentes concepciones de los procesos de enseñanza y aprendizaje de las matemáticas. La legitimidad, en este período, de la constitución de clases experimentales, hizo posibles experimentos y evaluaciones de este currículo de matemáticas en las escuelas de educación básica de la ciudad de Salvador, Bahía, Brasil.

Palabras clave: Movimiento de Matemática Moderna. Programa curricular de matemáticas. Experimentos pedagógicos

\section{INTRODUÇÃO}

As reformas educacionais ocorridas nas décadas entre 1950 e 1970 , e seus desdobramentos em diversos segmentos sociais e educacionais, são temas abordados na historiografia das ciências. No âmbito da historiografia da matemática, a esse período específico de reformas educacionais, convencionou-se chamar de Movimento da Matemática Moderna (MMM), cuja expressão traz consigo ações coletivas organizadas. Ações que se puseram em movimento, em busca de conquista e de convencimento de suas reivindicações.

Para tanto, essas ações coletivas constituíram-se em redes por onde transitavam pessoas, ideias e objetos permeando as diferentes culturas. Nesse período, essas pessoas, ideias e objetos circularam em diversos espaços e formas tais como eventos científicos, estágios acadêmicos, material impresso, correspondências, cursos, visitas acadêmicas, dentre outros. Foram marcos desse movimento o Seminário de Royaumont ${ }^{1}$ e as Conferências 
Interamericanas - no cenário internacional - e os encontros nacionais de ensino de matemática - no cenário brasileiro.

Por meio de pesquisas realizadas, tomando a Bahia como espaço geográfico do objeto de estudo, constatamos que, neste período histórico, um grupo formado por matemáticos e por professores de matemática, oriundos das diversas instituições e dos diferentes níveis da educação, possibilitou um trabalho de estudos, pesquisas, produções, experimentações e avaliações acerca da implementação de um projeto de reforma curricular para o ensino de matemática (CAMARGO, 2009; DIAS, 2001, 2002, 2008; FREIRE, 2008, 2009, 2017; FREIRE; DIAS, 2010a, 2010b; LANDO, 2012).

Esse grupo de matemáticos e de professores de matemática inicialmente desenvolveu suas atividades de estudo, ensino e pesquisa no âmbito da Universidade Federal da Bahia (UFBA) - Instituto de Matemática e Física (IMF), Faculdade de Filosofia (FF) e o Colégio de Aplicação (CA) - e das escolas da rede secundária. Em 1964, esse grupo assumiu a liderança dos cursos e das orientações de estudos para professores secundários em serviço, promovidos com o apoio financeiro da Superintendência do Desenvolvimento do Nordeste (SUDENE), em colaboração com a Secretaria de Educação da Bahia. Paralelo a essa formação docente em serviço, a equipe de profissionais começou a delinear um projeto baiano de reforma curricular para o ensino secundário de matemática que conformou as discussões que permearam os diversos fóruns nacionais e internacionais neste período. De acordo com Guimarães (2007), o programa internacional de atualização do ensino de matemática estava pautado em três ideias centrais: a unidade da matemática, o método axiomático e as estruturas matemáticas. Essas orientações ainda enfatizavam a “[...] valorização da Álgebra e da Geometria vectorial, com a correspondente desvalorização da Geometria de Euclides, na orientação axiomática dada ao estudo da Matemática, e numa valorização da linguagem e simbologia matemáticas" (GUIMARÃES, 2007, p. 32).

Com a implantação do Centro de Ensino de Ciências da Bahia (CECIBA), em finais do ano de 1965, o grupo baiano ampliou seus estudos, pesquisas e ações para mais um espaço. Na Secção Científica de Matemática do CECIBA, sob a coordenação de Martha Maria de Souza Dantas (1925-2011), foi possível sistematizar, consolidar, experimentar e avaliar esse projeto de reforma curricular para o ensino secundário de matemática, especificamente para o ensino ginasial (FREIRE, 2009, 2017; FREIRE, DIAS, 2010a).

Como um dos objetivos do CECIBA - edição de livros e periódicos sobre o ensino de ciências (CECIBA, 1965) - estava em consonância com as recomendações, pontuadas nos 
congressos internacionais - a produção, publicação e distribuição de textos, livros didáticos e traduções, destinados aos professores (CONFERÊNCIA INTERAMERICANA DE EDUCAÇÃO MATEMÁTICA, 1961) - para a renovação do ensino de matemática, isso possibilitou realizar o projeto de reforma curricular tendo, como um de seus vetores, a produção e a publicação de livros didáticos.

Ao sistematizar a proposta curricular, a equipe de professores de matemática do CECIBA estruturou, dentre os diversos projetos especiais desenvolvidos por esse Centro, nas diferentes áreas de conhecimento, o Projeto Especial de Matemática (PM 01) Desenvolvimento de um currículo de Matemática Moderna para o curso ginasial (CECIBA, 1966). Esse projeto já estava em elaboração desde 1964, tendo sido, inicialmente, constituído por um material, em forma de apostila, que foi utilizada em prática docente no CA. A partir da implementação do CECIBA e com a formação de classes experimentais ${ }^{2}$ em unidades escolares, na cidade de Salvador, acompanhadas por professores e estagiários desse Centro, é que esse projeto foi ampliado para outras escolas. Após avaliação, adequação e modificação dessas apostilas, oriundas das experimentações, esse material foi publicado a cada ano, sob editoração do CECIBA, em forma de livros didáticos, dando origem, no final, à coleção nomeada de Matemática Moderna, contendo na sua estrutura a reforma curricular proposta para o ensino secundário, especificamente para o ensino ginasial.

Martha Dantas, em documento de 24 de agosto de 1966, apresentou uma Exposição de Motivos ${ }^{3}$ solicitando a publicação do livro didático Matemática Moderna para $1 .{ }^{a}$ série ginasial. Dentre os motivos, ela argumentou que a publicação atenderia às "[...] recomendações, cada vez mais freqüentes, feitas pelas Conferências Interamericanas, Congressos Internacionais, Organização Européia de Cooperação Econômica, Seminário de Royaumont" (CECIBA, 1966, [s.p.]). Isso nos indica o entrelaçar de ações e ideias que estavam permeando a comunidade do ensino de matemática, nesse período.

Interpretando os vestígios e os traços encontrados, este artigo analisou historicamente a proposta do programa curricular de autoria do grupo de professores da Bahia, materializada na produção Coleção Matemática Moderna com saberes matemáticos e metodológicos, norteados pelas recomendações internacionais do MMM, de forma local, historicamente

\footnotetext{
${ }^{2}$ A partir de 1958, a legislação vigente passou a permitir a constituição de classes experimentais no ensino secundário (AMADO, 1958). Contudo, salientamos que o CECIBA constituiu suas classes para viabilizar suas propostas curriculares para o ensino das ciências e da matemática.

${ }^{3} \mathrm{O}$ destinatário não consta no documento. Possivelmente, foi dirigido ao Diretor Executivo do CECIBA para prováveis encaminhamentos.
} 
situados e com uma dinâmica social que acomodou as diferentes concepções sobre os processos de ensino e de aprendizagem em matemática.

Segundo Schubring (2003, p. 7), "Os livros destinados ao uso no ensino não são um tópico comum ou padrão da história da ciência". Entretanto, a partir de uma renovação na história das ciências, apontada por Pestre (1996) como análoga ao movimento que revolucionou a escrita da história na primeira metade do século $\mathrm{XX}$, podemos evidenciar uma renovação na historiografia das ciências na segunda metade do mesmo século. Para esse mesmo autor, essa renovação, que se iniciou em oposição à concepção de ciência dominante no mundo ocidental, apontava na direção de "[...] redefinir a natureza das práticas científicas" (PESTRE, 1996, p. 3). Com isso, novos objetos e novas abordagens despontaram como modos de expressão das ciências.

Ainda, de acordo com Pestre (1996), ao tratar dos novos objetos e das novas abordagens para a história das ciências, ele ressalta a intenção dele de fazer aparecer, " [...] por detrás da aparência de trivialidade ou de não pertinência, aqueles objetos escondidos que, no entanto, são essenciais para uma boa compreensão das práticas científicas" (PESTRE, 1996, p. 23). Além disso, o autor assinala que, atualmente, a história das ciências, recusa "[...] as noções passivas de difusão e recepção para reter aquelas, mais ativas, de representações e de apropriações historicamente situadas" (PESTRE, 1996, p. 28).

\section{A COLEÇÃO MATEMÁTICA MODERNA}

A produção dessa coleção foi coordenada pelo grupo de professores da Bahia, no âmbito do IMF e do CECIBA. Nesse sentido, logo a seguir, apresentamos o Quadro 1, em que estão organizados autores e editorações dos livros didáticos da Coleção Matemática Moderna, produzida pela equipe de professores da Bahia, na segunda metade da década de 1960.

\begin{tabular}{|l|l|l|l|l|}
\hline Título & Autores & Orientação & Editoração & Ano \\
\hline $\begin{array}{l}\text { Matemática } \\
\text { Moderna } I^{4}\end{array}$ & $\begin{array}{l}\text { Martha Maria de Souza Dantas, } \\
\text { Eliana Costa Nogueira, } \\
\text { Maria Augusta de Araújo Moreno }\end{array}$ & $\begin{array}{l}\text { Omar } \\
\text { Catunda }\end{array}$ & $\begin{array}{l}\text { Departamento Cultural } \\
\text { da Reitoria da UFBa }\end{array}$ & s/d \\
\hline
\end{tabular}

\footnotetext{
${ }^{4}$ As professoras Norma Coêlho de Araújo, Eunice da Conceição Guimarães, Neide Clotilde de Pinho e Souza constam como colaboradoras nesse volume.
} 


\begin{tabular}{|c|c|c|c|c|}
\hline $\begin{array}{l}\text { Matemática } \\
\text { Moderna II }\end{array}$ & $\begin{array}{l}\text { Martha Maria de Souza Dantas, } \\
\text { Eliana Costa Nogueira, } \\
\text { Norma Coêlho de Araújo, } \\
\text { Eunice da Conceição Guimarães, } \\
\text { Neide Clotilde de Pinho e Souza }\end{array}$ & $\begin{array}{l}\text { Omar } \\
\text { Catunda }\end{array}$ & $\begin{array}{l}\text { Centro de Ensino de } \\
\text { Ciências da Bahia- } \\
\text { Salvador }\end{array}$ & 1968 \\
\hline $\begin{array}{l}\text { Matemática } \\
\text { Moderna III }\end{array}$ & $\begin{array}{l}\text { Martha Maria de Souza Dantas, } \\
\text { Eliana Costa Nogueira, } \\
\text { Norma Coêlho de Araújo, } \\
\text { Eunice da Conceição Guimarães, } \\
\text { Neide Clotilde de Pinho e Souza }\end{array}$ & $\begin{array}{l}\text { Omar } \\
\text { Catunda }\end{array}$ & $\begin{array}{l}\text { Centro de Ensino de } \\
\text { Ciências da Bahia- } \\
\text { Salvador }\end{array}$ & 1969 \\
\hline $\begin{array}{l}\text { Matemática } \\
\text { Moderna } \\
\text { IV }^{5}\end{array}$ & $\begin{array}{l}\text { Omar Catunda, } \\
\text { Martha Maria de Souza Dantas, } \\
\text { Neide Clotilde de Pinho e Souza, } \\
\text { Eunice da Conceição Guimarães, } \\
\text { Eliana Costa Nogueira, } \\
\text { Norma Coêlho de Araújo }\end{array}$ & & $\begin{array}{l}\text { Centro de Ensino de } \\
\text { Ciências da Bahia } \\
\text { Universidade Federal } \\
\text { da Bahia }\end{array}$ & $\mathrm{s} / \mathrm{d}$ \\
\hline
\end{tabular}

Quadro 1- Relação dos componentes que integram a editoração da Coleção Matemática Moderna. Fonte: Adaptada, Arquivo do CECIBA, FACED-UFBA

Segundo Martha Dantas, a realização desse programa curricular só foi possível por terem na equipe o professor Omar Catunda (1906-1986), logo, justifica-se o destaque dado ao nome dele nos três primeiros volumes da Coleção como orientador (FREIRE, 2009, 2017). Além disso, o reconhecimento do trabalho do grupo foi registrado no instrumento de divulgação do CECIBA, em 1968 - Boletim do CECIBA.

[...] com a colaboração inestimável do Instituto de Matemática da Universidade Federal da Bahia, sob orientação do Professor Omar Catunda. [...] Deve-se ressaltar aqui o grande espírito de sacrifício de tôda a equipe, dirigida pela professôra Martha Maria de Souza Dantas que tornou possível o desenvolvimento dêsse trabalho (CECIBA, 1968, p. 2-3).

Ao iniciar a introdução do primeiro volume da Coleção, os autores apresentam uma citação retirada do livro L'enseignement des mathématiques, publicado pela Commission Internationale pour l'Etude et l'Amélioration de l'Enseignement des Mathématiques (CIEAEM), em 1955:

\begin{abstract}
Nós somos, ao mesmo tempo os espectadores e os atores de um acontecimento sem precedentes da história da Humanidade: a explosão crescente das Ciências, de tôdas as Ciências e, consequentemente, de tôdas as Tècnicas (DANTAS; NOGUEIRA; MORENO, [s.d.], v. I, p. III).
\end{abstract}

Destacamos a demarcação dos autores, por meio da citação no primeiro volume do livro, pela supremacia das ciências tão enaltecidas pelos argumentos que permearam as falas e

\footnotetext{
${ }^{5}$ Não existem indícios que comprovem a publicação desse último livro didático, encontramos uma impressão nos Arquivos do CECIBA com observações de correções a serem realizadas, todavia, poderemos supor que ele foi utilizado e avaliado, como era a prática do grupo, no ano de 1969, nas classes experimentais no Colégio de Aplicação e no Colégio Estadual Severino Vieira, pois essas escolas iniciaram o programa curricular, na primeira série ginasial, em 1965 e em 1966, respectivamente.
} 
os escritos nas décadas posteriores à Segunda Guerra Mundial. Como podemos constatar, a seguir, nos registros internacionais de 1961.

[...] difícil evitar que a ciência usa cada vez mais a matemática para a declaração e solução dos problemas mais difíceis. Neste contexto, o físico já é totalmente dependente da matemática e outras ciências evoluem claramente na mesma direção ${ }^{6}$ (ORGANIZAÇÃO EUROPEIA DE COOPERAÇÃO ECONÔMICA, 1961, p.18, tradução livre).

Na sequência dos argumentos, os autores da Coleção completam suas ideias, alinhados com os pronunciamentos e com os escritos de convencimento que perpassaram todas as reflexões em prol da modernização do ensino de matemática.

[...] a Ciência e a Técnica estão exigindo, cada vez mais, conhecimentos matemáticos [...] Por isso o ensino da Matemática precisou reformular-se em todos os seus níveis e, há mais de dez anos, iniciou a sua reestruturação em nível secundário (DANTAS; NOGUEIRA; MORENO, [s.d.], v. I, p. III).

O registro no documento resultante do Seminário de Royaumont, a seguir, constata a consonância entre as ideias dos professores de matemática da Bahia e as ideias que circulavam no âmbito internacional acerca da renovação dos conteúdos e métodos no ensino de matemática e, para tanto, o grupo decidiu produzir uma proposta de programa curricular, viabilizando-o por meio da produção de livros didáticos.

\begin{abstract}
Solicitam-se cada vez mais de pesquisadores e engenheiros, os quais devem ter sólidos conhecimentos matemáticos. As novas aplicações da matemática na indústria e em outros setores da economia solicitam mais matemáticos e que eles possuam conhecimentos novos. Todos esses fatores militam a favor de uma revisão de conteúdos e métodos no ensino de matemática, nos estabelecimentos escolares ${ }^{7}$ (ORGANIZAÇÃO EUROPEIA DE COOPERAÇÃO ECONÔMICA, 1961, p.11, tradução livre).
\end{abstract}

Em 1964, quando o grupo de professores do IMF elaborou o documento Plano Trienal (UFBA, 1964), deixou claro quais convicções acerca do ensino de matemática estavam requerendo para o planejamento dos cursos destinados aos professores de matemática, ao assinalar que era possível, por meio do ensino dos tópicos de Lógica, Conjunto e Estruturas, construir os conceitos básicos do conhecimento matemático no ensino superior. O grupo ainda ampliou essas mesmas convicções para o ensino secundário, ou seja, quando realizou a proposta de programa curricular para o curso ginasial assumiu essa tarefa, segundo os padrões

\footnotetext{
${ }^{6}[. .$.$] difficile de l'éviter que la science fait appel de façon croissante aux mathématiques pour l'énoncé et la$ solution de ses problèmes les plus difficiles. A cet égard la physique est déjà entièrement tributaire des mathématiques et les autres sciences évoluent de toute évidence dans le même sens.

${ }^{7}$ On demande de plus en plus de chercheurs et d'ingénieurs, qui tous doivent avoir de solides connaissances mathématiques. Les nouvelles applications des mathématiques dans l'industrie et dans les autres branches de l'activitè économique font que l'on demande davantage de mathématiciens et qu'on leur demande de posséder des connaissances nouvelles. Tous ces éléments militent en faveur d'une révision du contenu et des méthodes de l'enseignement des mathématiques, tel qu'il est donné dans les établissements scolaires. 
de modernização desse ensino, pois, de acordo com os autores da Coleção Matemática Moderna,

[...] a beleza da Matemática está na unidade, simplicidade e generalidade, que a caracterizam, por que não apresentá-la de cêdo, com tais atributos, aos jovens? (DANTAS; NOGUEIRA; MORENO, [s.d.], v. I, p. III-IV).

$[\ldots]$

Matemática de hoje [...] houve modificações na linguagem vulgar e na linguagem simbólica; novos têrmos e novos símbolos foram introduzidos [...] (DANTAS; NOGUEIRA; MORENO, [s.d.], v. I, p. III-IV).

$[\ldots]$

Com essa programação para o curso ginasial, espera-se que o aluno tenha compreendido o método da Matemática e tirado proveito do estudo estrutural da mesma que visa a uma simplificação cada vez maior do seu ensino (CATUNDA; DANTAS; SOUZA; GUIMARÃES; NOGUEIRA; ARAÚJO, [s/d], v. IV, p. III).

O que está implícito nas ideias reportadas é a concepção matemática preponderante no Seminário de Royaumont, isto é, os nortes da matemática estão na unidade, no método axiomático e no conceito de estruturas, precisamente na concepção bourbakista da matemática (GUIMARÃES, 2007; ORGANIZAÇÃO EUROPEIA DE COOPERAÇÃO ECONÔMICA, 1961). Segundo Gispert (2002, p. 42, tradução livre), “O mundo matemático desta reforma era o das estruturas, da axiomática e o formalismo matemático axiomático, que simboliza Bourbaki, [...] Mas é o mundo quase totalmente alheio aos professores do ensino secundário." $"$.

De acordo com uma das ideias centrais dessa prática matemática, os autores da Coleção Matemática Moderna seguiram a indicação do Seminário de Royaumont, em enfatizar os estudos da álgebra, pois, na introdução do segundo volume da Coleção, registram uma síntese dos conteúdos abordados no primeiro volume:

[...] estudou-se o conjunto dos naturais, as operações nêle definidas e suas propriedades estruturais. Continuando a seguir o processo histórico, na ampliação dos conjuntos de números, estudou-se, também, o conjunto dos racionais absolutos, operações nêle definidas e as propriedades estruturais relativas a estas operações. Dêste modo, duas estruturas foram ressaltadas: monóide e grupo [...] (DANTAS; NOGUEIRA; ARAÚJO; GUIMARÃES; SOUZA, 1968, v. II, p. III, grifo dos autores).

E, dando prosseguimento, sinalizam os estudos do segundo volume:

[...] são introduzidos os inteiros relativos, as operações definidas nêste conjunto e suas propriedades; surge uma nova estrutura: a estrutura de anel [...] são introduzidos os números racionais relativos $e$ ressaltadas suas estruturas de anel comutativo e corpo, relativamente à adição e à multiplicação [...] (DANTAS; NOGUEIRA; ARAÚJO; GUIMARÃES; SOUZA, 1968, v. II, p. III, grifo dos autores).

\footnotetext{
${ }^{8}$ Le monde mathématique de cette réforme est celui des structures, de l'axiomatique et du formalisme mathématique, celui que symbolise Bourbaki, [...] Mais c'est un monde presque totalement étranger au corps enseignant du secondaire.
} 
Poderíamos pensar que essas nomeações das estruturas algébricas pudessem ficar circunscritas à introdução, até porque a mensagem dos autores, na introdução dos livros, está muito mais direcionada para os professores do que para os alunos. Entretanto, não é isso o que ocorre, ao abordarem o conteúdo Números inteiros relativos, no capítulo III, do segundo volume, em que conceituam esse conjunto, definem a operação de adição e suas propriedades e concluem, apresentando-as, no corpo do livro, com o seguinte enunciado:

[...] o conjunto de números inteiros relativos é fechado, em relação à adição, e, além disso, esta operação goza da propriedade associativa, possui elemento neutro e cada elemento possui o seu oposto ou simétrico. Nestas condições, diz-se que o conjunto dos números inteiros relativos tem a estrutura de grupo, em relação à adição. Além disso, como a adição goza, também, da propriedade comutativa, dizse que o conjunto dos números inteiros relativos é um grupo abeliano (DANTAS; NOGUEIRA; ARAÚJO; GUIMARÃES; SOUZA, 1968, v. II, p. 96, grifo dos autores).

As citações, a seguir, mostram que, neste período, ainda persistia a dualidade entre um ensino secundário de caráter propedêutico, voltado para a minoria da elite, tendo-se em vista a continuidade dos estudos no ensino superior, em oposição ao ensino profissional de caráter terminal, voltado para as classes populares.

\footnotetext{
Nosso objetivo nêsse livro foi apresentar, desde o primeiro ano ginasial, aos jovens, a Matemática de hoje para que êles possam, amanhã, participar com entusiasmo, de uma Universidade renovada. Por isso houve modificações na linguagem vulgar e na linguagem simbólica; novos têrmos e novos símbolos foram introduzidos [...] (DANTAS; NOGUEIRA; MORENO, 1968, v. I, p. IV).

É preciso esclarecer, também, que essa preocupação de ressaltar as estruturas, o que se faz muito naturalmente, com um bom ensino, não é inovação despropositada. É um processo válido sob duplo aspecto: o formativo e o informativo. Pretende-se preparar os alunos para que não sofram, num ensino superior atualizado, o tremendo impacto criado por um ensino secundário tradicional (DANTAS; NOGUEIRA; ARAÚJO; GUIMARÃES; SOUZA, 1968, v. II, p. III).
}

Todavia, nos cruzamentos das similaridades encontram-se as diferenças. Elas emergem, trazendo seus traços e suas marcas culturais e sociais. O programa curricular para o ensino secundário, produzido pelo grupo de professores de matemática da Bahia, situa-se historicamente em um país que sempre foi marcado por exclusões sociais no percurso de sua história. No início da década de 1960, os números divulgados apresentavam as marcas da exclusão educacional em relação ao ensino secundário: nove por cento dos jovens brasileiros alcançavam esse nível educacional (VEJA, 1962).

Provavelmente, foi considerando essa realidade educacional, social e cultural brasileira, que os autores propuseram a inclusão de conhecimentos matemáticos, utilizados principalmente nas relações comerciais para compor o programa curricular.

[...] estudo da razão e proporção; este capítulo foi introduzido, levando em conta que muitos dos alunos do curso secundário o abandonam na $2^{a}$ série ginasial, quando procuram ocupações que exigem 
a aplicabilidade de tais conceitos (DANTAS; NOGUEIRA; ARAÚJO; GUIMARÃES, SOUZA, 1968, v. II, p. III).

Espera-se, também, que aquêles que não pretendam continuar os estudos do $2^{\circ}$ grau do curso secundário tenham adquirido a capacidade de resolver problemas que surjam nas suas futuras atividades (CATUNDA; DANTAS; SOUZA; GUIMARÃES; NOGUEIRA; ARAÚJO, [s.d.], v. IV, p. III).

É nessa seara de reflexões que podemos considerar Ginzburg (1987), quando afirma que as interpretações e as adaptações fazem parte de um movimento circular e é norteado por influências recíprocas.

Outro exemplo nesse sentido diz respeito à geometria. Nas décadas de 1950 e 1960, existiam duas vertentes, permeando as discussões acerca da atualização do ensino desse conhecimento. Segundo Guimarães (2007, p. 33), “[...] a maioria das propostas apresentadas [no Seminário de Royaumont] apontavam no sentido de uma abordagem algébrica da Geometria, para substituir os métodos tradicionalmente utilizados no seu estudo". De acordo com Fehr (1962), a primeira vertente estaria apoiada nos estudos de Birkhoff, que defendia a conservação da Geometria de Euclides, realizando as devidas correções aos seus axiomas. E a outra nos estudos de Klein, que defendia as transformações geométricas como abordagem da Geometria Euclidiana.

Apropriando-se dessas orientações, a equipe de professores da Bahia, na construção de sua proposta de programa curricular, optou pela introdução da estrutura algébrica do conjunto das transformações, ou seja, a geometria das transformações, como abordagem para o ensino de geometria no secundário - faixa etária dos 13 aos 15 anos. Em seus argumentos, inicialmente, faz uma incursão histórica da Geometria na Grécia antiga para subsidiar uma compreensão dos métodos clássico e moderno e, salienta: “à luz das ideias modernas da Matemática, podem-se distinguir duas linhas de pensamento" (CATUNDA, 1968. p. 1).

A primeira linha apontada é dada pelo teorema de Tales e suas deduções, que abrange “desde logo, a noção de paralelismo e de razão de segmentos de uma mesma reta". A segunda linha de pensamento é dada pela escola pitagórica e adotada por Euclides na elaboração da sua obra Os Elementos. Além disso, destaca que Euclides, na construção de seus tratados, considerou como ponto de partida "o conceito de igualdade de figuras, em particular, de segmentos quaisquer do plano. Como conseqüência, todos os segmentos podem ser medidos tomando como unidade de medida um segmento fixo" (CATUNDA, 1968. p. 1).

Após definir as bases das linhas de pensamento, Catunda (1968) argumenta que a definição de razão no teorema de Tales pode ser por meio de translações na reta, e "a demonstração da igualdade das razões depende da igualdade de triângulos que se 
correspondem por translações na direção das paralelas, ou das retas dadas". E sinaliza que, para construir esse conhecimento matemático, bastam as propriedades afins do plano que, por sua vez, advêm da estrutura de espaço vetorial do conjunto das translações. Nesse contexto, a construção inicial do pensamento geométrico, ou seja, o ensino da geometria elementar não precisa estar pautado nas ideias "de comparação de ângulos, de ortogonalidade, de comparação de segmentos não paralelos, etc" (CATUNDA, 1968. p. 1). Por essa ótica, é que os autores propuseram o seu programa curricular, tal como podemos observar em suas próprias palavras:

No terceiro ano ginasial, estudam-se, primeiramente, as transformações na reta. Em seguida, partindo da observação e tomando por base propriedades bastante intuitivas, introduz-se a estrutura de espaço vetorial do conjunto das translações no plano. O conjunto dos pontos do plano é, então, o espaço afim bi-dimensional associado ao espaço vetorial assim definido. Desta maneira se apresentam, naturalmente, às coordenadas cartesianas ligadas a um sistema de referência [...]. Estudam-se, então, [...] as figuras geométricas que não dependem do conceito de distância, isto é, que são conceitos afins [...] (DANTAS; NOGUEIRA; ARAÚJO; GUIMARÃES; SOUZA, v. III, 1969, p. III - IV).

Em seguida à exploração da parte linear - espaços vetorial e afim de duas dimensões , por meio da simetria axial, é iniciada a parte métrica da Geometria Elementar. De acordo com os autores da proposta do programa curricular, a estrutura de conteúdos, conceitos e métodos "permite preparar o caminho para o estudo da Matemática superior que, atualmente, se baseia, sobretudo, no conceito de linearidade" (CATUNDA; DANTAS; SOUZA; GUIMARÃES; NOGUEIRA; ARAÚJO, [s/d], v. IV, p. III).

As classes experimentais, selecionadas e locadas em algumas das escolas de Salvador, representavam espaços, coordenados pelo CECIBA, onde era experimentada e avaliada a proposta do programa curricular para o ensino de Matemática. Alguns colégios baianos podem ser citados como instituições que desenvolveram essas experiências no seu ensino secundário, tais como, Colégio Estadual Severino Vieira, Colégio Manoel Devoto, CA, Colégio Estadual Luiz Pinto de Carvalho, Colégio Antônio Vieira e Colégio Nossa Senhora do Carmo. Uma vez que esses dois últimos colégios, citados, eram da rede privada, logo, podemos concluir que a inserção do CECIBA não se limitava à rede pública educacional (FREIRE, 2009). Na sequência, detalhamos um pouco a experimentação realizada no CA.

\section{A EXPERIMENTAÇÃO NO COLÉGIO DE APLICAÇÃO DA UFBA}

O Colégio de Aplicação da Universidade da Bahia, criado em 1944, desenvolveu suas atividades no período de 1949 a 1976, tendo como finalidades principais servir à prática 
docente e aos estágios dos licenciandos da FF, e ainda, servir de campo de experimentação pedagógica para esta Faculdade (FF, 1944).

A experimentação pedagógica, desenvolvida pelo grupo de matemáticos e de professores de matemática baianos nas décadas de 1960 e 1970, no CA, no que se refere a conteúdos e métodos introduzidos por meio dessa experiência, ressaltava: a teoria dos conjuntos, o papel das estruturas na síntese dos ramos da matemática, o método axiomático, o conceito de linearidade e das transformações geométricas, bem como a lógica matemática.

A teoria dos conjuntos, na 1. ${ }^{\text {a }}$ série ginasial, aparece de forma regular no ano de 1965 - há uma constância maior destes conteúdos no decorrer do ano letivo - e não foi trabalhada somente no início do ano, como ocorreu até o ano de 1964, mas retomada a cada novo conjunto numérico abordado. Ao comparar os conteúdos registrados no diário de classe de

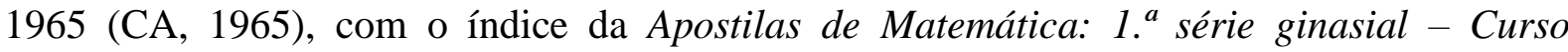
experimental segundo os novos métodos do ensino da Matemática (DANTAS; NOGUEIRA; MORENO, 1966), publicada em fevereiro de 1966, percebemos quase a totalidade de elementos em comum; somente um ou outro item dos seis primeiros capítulos e parte do último capítulo da apostila não estão registrados no diário de classe. Assim, interpretamos que, neste ano de 1965, já se iniciou uma experiência sistematizada, envolvendo conceitos da Matemática Moderna no CA, mediante a atuação da professora Maria Augusta Araújo Moreno, uma das autoras da referida apostila.

Esta suposição acerca do início da experimentação da apostila no ano de 1965 se fortalece, ao considerarmos o que as autoras escreveram na introdução do livro Matemática Moderna I: "Êste livro já foi experimentado dois anos e os resultados que apresentaremos, em breve, aos professôres, são bastante animadores" (DANTAS; NOGUEIRA; MORENO, [s/d], v. I, p. IV).

Nos anos de 1967 a 1974 (CA, 1967a - 1974a), na 2. a série ginasial, foram ensinados os conteúdos do livro Matemática Moderna II. Nessa série, deu-se continuidade à teoria dos conjuntos, abordando o conjunto dos números inteiros relativos e racionais relativos - as operações neles definidas e as propriedades estruturais. Os conteúdos foram desenvolvidos sob uma linguagem algébrico-conjuntista, como apontados por Guimarães (2007), ao referirse aos elementos de uma modernização da matemática para o ensino secundário. Assim, as retas do plano são conjuntos de pontos; os números, classes de equivalência; as operações, aplicações. 
$\mathrm{Na} 3 .^{\mathrm{a}}$ série ginasial, as experimentações começaram no ano de $1968^{9}$ (CA, 1968b). Iniciou-se com noções de Lógica. Depois trabalharam-se números reais e reta. Por fim, introduziu-se a geometria das transformações, modificando toda a abordagem do ensino de geometria até então vigente. Por esses aspectos, nessa série foram efetivadas as mudanças mais significativas submetidas pelos autores da Coleção referentes à proposta de programa curricular.

Na 4. ${ }^{\text {a }}$ série ginasial, nos anos de 1969 e 1970 (CA, 1969b; 1970b), foi utilizado o livro Matemática Moderna IV e, posteriormente, até o ano de 1976 (CA, 1971b-1974b; 1975; 1976), o livro Ensino Atualizado da Matemática 4, curso ginasial (CATUNDA; DANTAS; NOGUEIRA; ARAÚJO; GUIMARÃES; SOUZA; MORENO, 1971), como recurso didático no ensino de matemática dessa série.

A proposta dos autores em relação à $4 .^{\mathrm{a}}$ série ginasial era dar prosseguimento ao estudo da geometria euclidiana do plano iniciada na 3. ${ }^{\text {a }}$ série. Em suas próprias palavras:

\begin{abstract}
A Geometria euclidiana, também iniciada em Matemática Moderna III onde se estuda o capítulo "distâncias e polígonos", continua no estudo do círculo, da extensão da noção de ângulo, das relações métricas num triângulo e no círculo, dos polígonos regulares e áreas dos polígonos. [...] Depois de completado o estudo da geometria clássica, elementar, no plano, estuda-se a equação do $2^{\circ}$ grau, [...] finalmente, faz-se um estudo simplificado do cálculo de radicais [...] (CATUNDA; DANTAS; SOUZA; GUIMARÃES; NOGUEIRA; ARAÚJO, [s/d], v. IV, p. III-IV, grifo dos autores).
\end{abstract}

Posteriormente, os autores, ao publicarem o Guia do Professor da Coleção Ensino Atualizado da Matemática, fizeram uma alerta em relação à 8. ${ }^{a}$ série, afirmando que: "Aqui, o programa permanece bastante clássico mudando, apenas, a sua abordagem." (CATUNDA; DANTAS; NOGUEIRA; ARAÚJO; GUIMARÃES; SOUZA; MORENO, 1974, p. 54). Acerca dessa abordagem, entre outras, trata-se de estudar as relações métricas no círculo por meio das transformações geométricas, mais especificamente, das simetrias - central e axial -; destacar o grupo das rotações, ao abordar a extensão da noção de ângulo; e empregar as noções de conjunto, em especial, conjunto solução, ao estudar as equações do $2 .^{\circ}$ grau (CATUNDA; DANTAS; NOGUEIRA; ARAÚJO; GUIMARÃES; SOUZA; MORENO, 1974).

O Quadro 2 mostra, resumidamente, os indícios da experimentação da proposta do programa curricular no curso ginasial do CA que apresentamos, anteriormente, mediante análise dos diários de classe e dos livros adotados.

9 O livro Matemática Moderna III foi publicado no ano seguinte. (DANTAS; NOGUEIRA; ARAÚJO;
GUIMARÃES; SOUZA, 1969, v. III). Universidade Federal de Mato Grosso, Cuiabá, Mato Grosso, Brasil. Revista REAMEC - Rede Amazônica de Educação em Ciências e Matemática, v. 9, n. 3, e21092, setembro-dezembro, 2021. 


\begin{tabular}{|c|c|c|c|c|}
\hline Anos & 1. ${ }^{\mathrm{a}}$ série & 2. ${ }^{\mathrm{a}}$ série & 3. ${ }^{\mathrm{a}}$ série & 4. ${ }^{\mathrm{a}}$ série \\
\hline $\begin{array}{l}\frac{b}{5} \\
\frac{a}{\pi} \\
6 \\
2 \\
2\end{array}$ & $\begin{array}{l}1965 \text { a } 1973 \\
\text { Conjuntos dos } \\
\text { números naturais e } \\
\text { racionais absolutos } \\
- \text { as operações } \\
\text { neles definidas e as } \\
\text { propriedades } \\
\text { estruturais relativas } \\
\text { a estas operações } \\
\text { (monóide e grupo) }\end{array}$ & 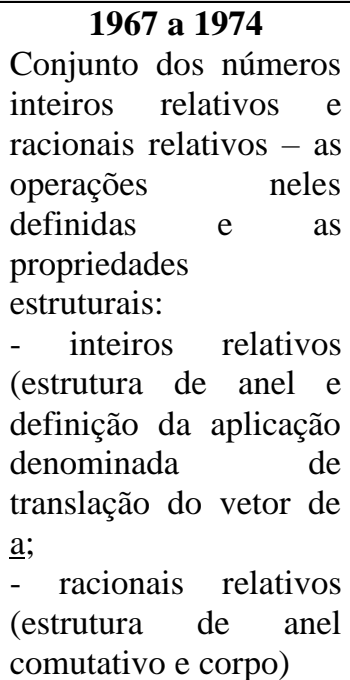 & 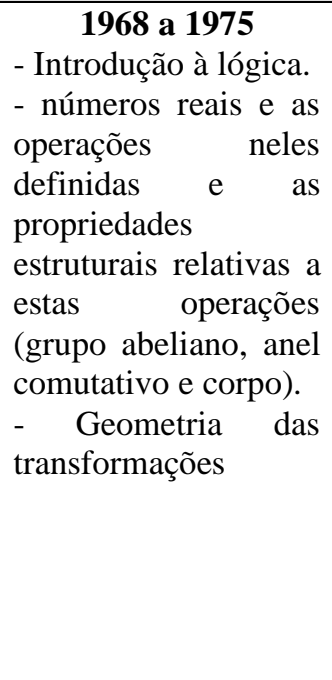 & $\begin{array}{l}\text { 1969 a } 1976 \\
\text { Priorizou-se mudanças } \\
\text { na abordagem dos } \\
\text { conceitos. Dentre outras: } \\
\text { - relações métricas do } \\
\text { círculo por meio das } \\
\text { transformações } \\
\text { geométricas (simetrias: } \\
\text { central e axial) } \\
\text { - destacar o grupo das } \\
\text { rotações ao abordar a } \\
\text { noção de ângulo; } \\
\text { Empregar as noções de } \\
\text { conjunto ao estudar as } \\
\text { equações do } 2^{\circ} \text { grau. }\end{array}$ \\
\hline
\end{tabular}

Quadro 2 - Vestígios das experimentações no curso ginasial.

Fonte: Elaborado por Lando (2012)

Observando o quadro sinóptico apresentado, interpretamos que as mudanças mais significativas ocorreram nas $1 .^{a}$ e $3 .^{a}$ séries, considerando que se introduziu a teoria dos conjuntos na $1 .^{\mathrm{a}}$ série; e, na $3 .^{\mathrm{a}}$, a introdução à lógica e à geometria das transformações. $\mathrm{Na} 2 .^{\mathrm{a}}$ série, dava-se continuidade à teoria dos conjuntos, ao abordar outros dois conjuntos numéricos, e na $4 .^{\text {a }}$, para além de alguns aspectos da matemática clássica, utilizavam-se conceitos da geometria das transformações e teoria dos conjuntos para ensinar trigonometria e equações. Constatamos, ainda, que as experimentações foram iniciadas a cada ano uma nova série.

A respeito dessa experimentação no CA, posteriormente, Dantas (apud GARNICA, 2008, p. 186) fez a seguinte avaliação:

Estas programações, que poderiam parecer utópicas para os que ainda não tinham vivência de ensino que utilizava noções fundamentais da chamada Matemática Moderna, foram bem sucedidas quando da aplicação dos referidos textos a partir de 66 num colégio de aplicação da Universidade Federal da Bahia. A experiência foi considerada de alto nível, mas não fracassou porque os professores que a realizaram no referido colégio estavam preparados para ela e os alunos que dela participaram tinham condições de suportá-la.

Contudo, apesar de uma forte mobilização seja no contexto da própria UFBA, no processo de formação dos futuros professores de matemática, seja na inserção de classes experimentais nas escolas, seja, ainda, nos cursos de formação do professor em serviço, houve resistência em uma apropriação das coleções elaboradas pela equipe de professores da Bahia (DANTAS, 1971). Os motivos alegados eram diversos, mas o mais recorrente foi a falta de domínio da linguagem excessivamente simbólica, que ganhou notoriedade com a publicação 
do livro O fracasso da matemática moderna, de autoria de Morris Kline, em 1976, acentuando as críticas em relação a uma modernização do ensino secundário da matemática, ocorrida a partir da segunda metade do século XX (GOMES, 2014). Foi, por certo, um elemento significativo em nível internacional. Mas, na Bahia, contribuíram ainda alguns outros fatores. Ao final da própria década de 1960 e ao longo da década de 1970, as iniciativas em torno de novas experimentações para o ensino de matemática foram sendo paulatinamente desmanteladas pelo fim das atividades do CECIBA (1969) e do PROTAP (1974). Talvez, todos esses elementos expliquem o fato de que a proposta do programa curricular da equipe de professores da Bahia não tivesse obtido o êxito esperado, sendo apropriado somente em locais muito específicos, na maioria, por professores formados ou que tiveram uma formação continuada com os idealizadores dessa proposta, como exemplo, posterior à década de 1970, o caso do Instituto Nossa Senhora da Piedade, em Ilhéus, Bahia (GOMES, 2014).

\section{CONSIDERAÇÕES FINAIS}

O grupo de professores de matemática da Bahia, liderado por Martha Dantas e Omar Catunda, foi bastante ativo. Na década de 1960, propôs um programa curricular para modernizar o ensino de matemática, materializado, inicialmente, na produção da Coleção Matemática Moderna com saberes matemáticos e metodológicos norteados pelas recomendações internacionais do MMM e, posteriormente, ao longo da década de 1970, na produção de novas coleções sempre tomando como ponto de partida as experimentações feitas em anos anteriores, alicerçadas nos resultados alcançados nas classes experimentais em escolas da educação secundária, na cidade de Salvador, Bahia, mas, principalmente, nas críticas manifestadas pelos professores que conduziram tais experimentações.

Constatamos que a Coleção Matemática Moderna foi estruturada a partir das concepções dos autores sobre os processos de ensino e de aprendizagem em matemática, tornando-se, assim, uma proposta curricular localmente situada, considerando tanto a conjuntura educacional baiana, nesse período, como a rede internacional por onde circulavam pessoas, ideias e objetos das diferentes culturas.

Para além dessas coleções, a equipe realizou cursos de treinamento de formação continuada de professores. Tratava-se de um movimento duplo, mas articulado: por um lado, buscava-se certa hegemonia do ensino de matemática a partir de um ideário modernizador da 
matemática escolar; por outro, formar uma rede de professores, alinhados a essas ideias algébrico-conjuntista da matemática.

\section{REFERÊNCIAS}

AMADO, G. Instruções sôbre a natureza e a organização das classes experimentais, da Diretoria do Ensino Secundário. Classes Experimentais no Ensino Secundário. Revista Brasileira de Estudos Pedagógicos, n. 72, v. XXIX, p. 73-83, abr./jun. 1958.

CA [COLÉGIO DE APLICAÇÃO]. Diário de classe $-1^{\text {a }}$ série ginasial. Salvador: FACED/UFBA, 1965.

CA [COLÉGIO DE APLICAÇÃO]. Diário de classe $-2^{\mathrm{a}}$ série ginasial. Salvador: FACED/UFBA, 1967a - 1974a.

CA [COLÉGIO DE APLICAÇÃO]. Diário de classe - $3^{\mathrm{a}}$ série ginasial. Salvador: FACED/UFBA, 1968b.

CA [COLÉGIO DE APLICAÇÃO]. Diário de classe - $4^{\mathrm{a}}$ série ginasial. Salvador: FACED/UFBA, 1969b - 1974b; 1975; 1976.

CAMARGO, K.C. O ensino de geometria nas coleções didáticas em tempos do Movimento da Matemática Moderna na capital da Bahia. 2009. 168 f. Dissertação (Mestrado em Educação Matemática) - Universidade Bandeirante de São Paulo, São Paulo. 2009. Disponível em: https://repositorio.ufsc.br/bitstream/handle/123456789/186655/K\%c3\%81TIA\%20CAMARG O.pdf?sequence $=1 \&$ isAllowed=y. Acesso em: 27 out. 2021.

CATUNDA, O. Uma Experiência no Ensino de Geometria. Boletim do CECIBA, Salvador, n. 8, dez. 1968. [Arquivo do CECIBA, FACED-UFBA].

CATUNDA, O.; DANTAS, M. M. S.; SOUZA, N. C. P.; GUIMARÃES, E. C.; NOGUEIRA, E. C.; ARAÚJO, N. C. Matemática Moderna IV. Salvador: CECIBA/UFBA, [s/d].

CATUNDA, O.; DANTAS, M. M. S.; NOGUEIRA, E. C.; ARAÚJO, N. C.; GUIMARÃES, E. C.; SOUZA, N. C. P.; MORENO, M. A. A. Ensino Atualizado da Matemática 4. São Paulo: EDART, 1971.

CATUNDA, O.; DANTAS, M. M. Souza; NOGUEIRA, E. C.; ARAÚJO, N. C.; GUIMARÃES, E. C.; SOUZA, N. C. P.; MORENO, M. A. A. Ensino Atualizado da Matemática: $5^{\mathrm{a}}$ a $8^{\mathrm{a}}$ séries do primeiro grau, Guia para o professor. São Paulo: EDART, 1974.

CECIBA [CENTRO DE ENSINO DE CIÊNCIAS DA BAHIA]. Resolução de implantação do CECIBA. Salvador: FACED/Universidade Federal da Bahia, 17 nov. 1965.

CECIBA [CENTRO DE ENSINO DE CIÊNCIAS DA BAHIA]. Relatório das atividades da SCM. Salvador: FACED/Universidade Federal da Bahia, jan./maio 1966. 
CECIBA [CENTRO DE ENSINO DE CIÊNCIAS DA BAHIA]. Exposição de Motivos para a publicação dos textos do SCM. Salvador: FACED/Universidade Federal da Bahia, 1966.

CECIBA [CENTRO DE ENSINO DE CIÊNCIAS DA BAHIA]. Boletim do CECIBA, Salvador, n. 8, dez. 1968. Salvador: FACED/ Universidade Federal da Bahia.

CONFERÊNCIA INTERAMERICANA DE EDUCAÇÃO MATEMÁTICA, 1., 1961, Bogota. Primeira Conferencia Inter-americana sobre la Educacion de las Matematicas. Anais [...]. FEHR, H. F. (Org.). BUREAU OF PUBLICATIONS: Teachers College, Columbia University, 1962; Mathématiques Nouvelles. Paris: OECE, 1961. p.14-30.

DANTAS, M. M. S. Sôbre a metodologia da matemática. Tese apresentada ao concurso para professor titular da UFBA. Universidade Federal da Bahia, Salvador, 1971.

DANTAS, M. M. S.; NOGUEIRA, E. C.; MORENO, M. A. A. Supervisão: O. Catunda. Apostilas de matemática: $1^{a}$ série ginasial - Curso Experimental segundo os novos métodos do ensino da Matemática. Salvador: UFBA/CECIBA, 1966.

DANTAS, M. M. S.; NOGUEIRA, E. C.; MORENO, M. A. A. Orientação: O. Catunda. Matemática Moderna I. Salvador: UFBA, [s/d].

DANTAS, M. M. S.; NOGUEIRA, E. C.; ARAÚJO, N. C.; GUIMARÃES, E. C.; SOUZA, N. C. P. Orientação: O. Catunda. Matemática Moderna II. Salvador: CECIBA, 1968.

DANTAS, M. M. S.; NOGUEIRA, E. C.; ARAÚJO, N. C.; GUIMARÃES, E. C.; SOUZA, N. C. P. Orientação: O. Catunda. Matemática Moderna III. Salvador: CECIBA, 1969.

DIAS, A. L. M. As fundadoras do Instituto de Matemática e Física da Universidade da Bahia. História, Ciência e Saúde - Manguinhos, Rio de Janeiro, v. 7, n. 3, p. 653-674, 2001. https://doi.org/10.1590/S0104-59702001000600005

DIAS, A. L. M. Engenheiros, Mulheres, Matemáticos: interesses e disputas na profissionalização da matemática na Bahia (1896-1968). 2002. 320 f. Tese (Doutorado em História Social) - Faculdade de Filosofia, Letras e Ciências Humanas, Universidade de São Paulo, São Paulo, 2002. Disponível em: https://teses.usp.br/teses/disponiveis/8/8138/tde09062002-091012/publico/Tese.pdf. Acesso em: 27 out. 2021.

DIAS, A. L. M. O Instituto de Matemática e Física da Universidade da Bahia: atividades matemáticas (1960-1968). História, Ciências, Saúde - Manguinhos, Rio de Janeiro, v.15, n.4, p.1049-1075, out./dez. 2008. https://doi.org/10.1590/S0104-59702008000400010.

FEHR, H. F. Reforma de la enseñanza de la geometria. In: CONFERÊNCIA

INTERAMERICANA DE EDUCAÇÃO MATEMÁTICA , 1., 1961, Bogotá. Anais [...]. Fehr, H. F. (org.). Bureau of Publications: Teachers College, Columbia University, 1962.

FF [FACULDADE DE FILOSOFIA]. Regimento do Ginásio Anexo da Faculdade de Filosofia da Bahia. Salvador: Imprensa Oficial, 1944. 
FREIRE, I. A. A. Ensino de Ciências e Matemática: processos de institucionalização e modernização na década de 1960. 2017. 111 f. Tese (Doutorado em Ensino, Filosofia e História das Ciências)- Universidade Federal da Bahia, Instituto de Física, Salvador, 2017. Disponível em:

https://repositorio.ufba.br/ri/bitstream/ri/31474/1/FREIRE\%20TESE\%20VERS\%c3\%830\%2 0FINAL.pdf. Acesso em: 27 out. 2021.

FREIRE, I. A. A. Matemática moderna e seu ensino no secundário: circulação de idéias nos anos 60 na Bahia. In: CONGRESSO LUSO-BRASILEIRO DE HISTÓRIA DA EDUCAÇÃO, 7., 2008, Porto. Actas [...]. Porto, Portugal: Sociedade Portuguesa de Ciências da Educação. 2008.

FREIRE, I. A. A. Ensino de Matemática: iniciativas inovadoras no Centro de Ensino de Ciências da Bahia (1965-1969). 2009. 102 f. Dissertação (Mestrado em Ensino, Filosofia e História das Ciências)- Instituto de Física, Universidade Federal da Bahia, Salvador, 2009. Disponível em:

https://repositorio.ufba.br/ri/bitstream/ri/16023/1/In\%c3\%aas\%20Ang\%c3\%a9lica\%20Andra de\%20Freire.pdf. Acesso em: 27 out. 2021.

FREIRE, I. A. A.; DIAS, A. L. M. Seção Científica de Matemática do CECIBA: propostas e atividades de renovação do ensino secundário de matemática (1965-1969). BOLEMA Boletim de Educação Matemática, Rio Claro, v. 23, n. 35b, p.363-386, abr. 2010a. Disponível em:

https://www.periodicos.rc.biblioteca.unesp.br/index.php/bolema/article/view/3758. Acesso em: 27 out. 2021.

FREIRE, I. A. A; DIAS, A. L. M.. Um Encontro Promissor para o Ensino de Matemática na Bahia: pesquisas e realizações na década de 60 do séc. XX. In: FLORES, C.; ARRUDA, J. P. (Org.). A Matemática Moderna nas escolas do Brasil e Portugal: contribuições para a história da educação matemática. São Paulo: Annablume. 2010b. p. 143-155.

GARNICA, A. V. M. Resgatando Oralidades para a história da Matemática e da Educação Matemática brasileiras: o Movimento da Matemática Moderna. Zetetiké - Cempem - FE Unicamp, v. 16, n. 30, jul./dez. 2008. Disponível em:

https://periodicos.sbu.unicamp.br/ojs/index.php/zetetike/article/view/8646895/13797 . Acesso em: 27 out. 2021. Doi: https://doi.org/10.20396/zet.v16i30.8646895

GINZBURG, C. O Queijo e os Vermes. São Paulo: Companhia das Letras, 1987.

GISPERT, H. Pourquoi, pour qui enseigner les mathématiques? Une mise en perspective historique de l'évolution des programmes de mathématiques dans la société française au XXe siècle. Bulletin l'APMEP, Dossier "Histoire de l'enseignement des mathématiques", n. 438, p. 36-48, janvier 2002. Disponível em: https://www.apmep.fr/IMG/pdf/AAA02005.pdf. Acesso em: 27 out. 2021.

GOMES, L. P. S. Entre a Exposição e a Descoberta: a coleção Matemática e as práticas escolares relacionadas à sua utilização no Instituto Nossa Senhora da Piedade. 2014. 248 f. Tese (Doutorado em Educação) - Universidade Estadual de Campinas, Campinas, São Paulo, 2014. Disponível em: 
http://repositorio.unicamp.br/bitstream/REPOSIP/319166/1/Gomes_LarissaPincaSarro_D.pdf.

Acesso em: 27 out. 2021.

GUIMARÃES, H. M. Por uma Matemática nova nas escolas secundárias: perspectivas e orientações curriculares da matemática moderna. In: MATTOS, J. M; VALENTE, W. R. (Org.). A Matemática Moderna nas escolas do Brasil e de Portugal: primeiros estudos. São Paulo: Editora Da Vinci/Capes/Ghemat, 2007.

LANDO, J. C. Práticas, inovações, experimentações e competências pedagógicas das professoras de matemática no Colégio de Aplicação da Universidade da Bahia (19491976). 2012. 307 f. Tese (Doutorado em Ensino, Filosofia e História das Ciências) - Instituto de Física, Universidade Federal da Bahia/Universidade Estadual de Feira de Santana, Salvador, 2012. Disponível em: https://ppgefhc.ufba.br/sites/ppgefhc.ufba.br/files/tese_janice_lando.pdf. Acesso em: 27 out. 2021.

\section{ORGANIZAÇÃO EUROPÉIA DE COOPERAÇÃO ECONÔMICA. Mathématiques}

Nouvelles. Paris: OECE, 1961.

PESTRE, D. Por uma nova história social e cultural das ciências: novas definições, novos objetos, novas abordagens. Cadernos IG-Unicamp, v. 6, n. 1, p. 3-56, 1996.

SCHUBRING, G. Análise histórica de livros de matemática: notas de aula. Campinas, SP: Autores Associados, 2003.

UFBA [UNIVERSIDADE FEDERAL DA BAHIA]. Planos Trienais, 1965-1967, Boletim Informativo da UBa, Ano IX, n. 97, p.19-33, nov. 1964. Salvador, Arquivo da UFBA.

VEJA. São Paulo: Ed. Abril, Edição Especial, out. 1962. Disponível em: http://veja.abril.com.br/historia/crise-dos-misseis/indice.shtml. Acesso em: 15 jan. 2008.

\section{APÊNDICE 1}

\section{AGRADECIMENTOS}

Não se aplica.

FINANCIAMENTO

Não houve financiamento.

\section{CONTRIBUIÇÕES DE AUTORIA}

Resumo/Abstract/Resumen: Inês Angélica Andrade Freire, Janice Cassia Lando e Eliene Barbosa Lima. Introdução: Inês Angélica Andrade Freire, Janice Cassia Lando e Eliene Barbosa Lima.

Referencial teórico: Inês Angélica Andrade Freire, Janice Cassia Lando e Eliene Barbosa Lima.

Análise de dados: Inês Angélica Andrade Freire, Janice Cassia Lando e Eliene Barbosa Lima.

Discussão dos resultados: Inês Angélica Andrade Freire, Janice Cassia Lando e Eliene Barbosa Lima.

Conclusão e considerações finais: Inês Angélica Andrade Freire, Janice Cassia Lando e Eliene Barbosa Lima.

Referências: Inês Angélica Andrade Freire, Janice Cassia Lando e Eliene Barbosa Lima.

Revisão do manuscrito: Vera Lúcia Fator Gouvêa Bonilha.

Aprovação da versão final publicada: Inês Angélica Andrade Freire, Janice Cassia Lando e Eliene Barbosa Lima. 
CONFLITOS DE INTERESSE

Os autores declararam não haver nenhum conflito de interesse de ordem pessoal, comercial, acadêmico, político e financeiro referente a este manuscrito.

\section{DISPONIBILIDADE DE DADOS DE PESQUISA}

O conjunto de dados que dá suporte aos resultados da pesquisa foi publicado no próprio artigo.

\section{CONSENTIMENTO DE USO DE IMAGEM}

Não se aplica.

\section{APROVAÇÃO DE COMITÊ DE ÉTICA EM PESQUISA}

Não se aplica.

\section{COMO CITAR - ABNT}

FREIRE, Inês Angélica Andrade; LANDO, Janice Cassia; LIMA, Eliene Barbosa. Programa curricular para o ensino de matemática na década de 1960 - Salvador/Bahia. REAMEC - Rede Amazônica de Educação em Ciências e Matemática. Cuiabá, v. 9, n. 3, e21092, set./dez., 2021. https://doi.org/10.26571/reamec.v9i3.13108

\section{COMO CITAR - APA}

Freire, I. A. A., Lando, J. C., \& Lima, E. B. (2021). Programa curricular para o ensino de matemática na década de 1960 - Salvador/Bahia. REAMEC - Rede Amazônica de Educação em Ciências e Matemática, 9(3), e21092. https://doi.org/10.26571/reamec.v9i3.13108

\section{LICENÇA DE USO}

Licenciado sob a Licença Creative Commons Attribution-NonCommercial 4.0 International (CC BY-NC 4.0). Esta licença permite compartilhar, copiar, redistribuir o manuscrito em qualquer meio ou formato. Além disso, permite adaptar, remixar, transformar e construir sobre o material, desde que seja atribuído o devido crédito de autoria e publicação inicial neste periódico.

\section{DIREITOS AUTORAIS}

Os direitos autorais são mantidos pelos autores, os quais concedem à Revista REAMEC - Rede Amazônica de Educação em Ciências e Matemática - os direitos exclusivos de primeira publicação. Os autores não serão remunerados pela publicação de trabalhos neste periódico. Os autores têm autorização para assumir contratos adicionais separadamente, para distribuição não exclusiva da versão do trabalho publicada neste periódico (ex.: publicar em repositório institucional, em site pessoal, publicar uma tradução, ou como capítulo de livro), com reconhecimento de autoria e publicação inicial neste periódico. Os editores da Revista têm o direito de proceder a ajustes textuais e de adequação às normas da publicação.

\section{PUBLISHER}

Universidade Federal de Mato Grosso. Programa de Pós-graduação em Educação em Ciências e Matemática (PPGECEM) da Rede Amazônica de Educação em Ciências e Matemática (REAMEC). Publicação no Portal de Periódicos UFMT. As ideias expressadas neste artigo são de responsabilidade de seus autores, não representando, necessariamente, a opinião dos editores ou da referida universidade.

\section{EDITOR}

Dailson Evangelista Costa (iD)

\section{HISTÓRICO}

Submetido: 22 de setembro de 2021.

Aprovado: 20 de outubro de 2021.

Publicado: 06 de novembro de 2021. 